\title{
Faculty Adoption of Teaching and Learning Technologies: Contrasting Earlier Adopters and Mainstream Faculty
}

\section{TERRY ANDERSON, STANLEY VARNHAGEN \& KATY CAMPBELL}

University Of Alberta

\section{ABSTRACT}

The adoption of teaching and learning technologies is an innovation that challenges the structure, culture and practice of modern research universities. This paper documents quantitatively and qualitatively the attitudes, skills and behavior of the faculty related to the use of instructional technology at a large Canadian research university. The data was gathered from a survey $(n=557)$ of teaching faculty. The data is analyzed with respect to Roger's (1995) categories of adoption of innovation differentiating "Earlier Adopters" (EAs) from "Mainstream Faculty" $(\mathrm{MF})$. The paper discusses four factors that have tended to create a "chasm" between these two groups and discusses strategies for reducing the chasm and providing support and incentive for all faculty in the adoption of instructional technologies.

\section{RÉSUMÉ}

L'adoption de la technologie éducative à des fins pédagogiques constitue une innovation qui remet en question la structure, la culture et les pratiques des universités de recherche modernes. Cet article présente des données qualitatives et quantitatives sur les attitudes, les habitudes et 
le comportement de professeurs d'une grande université de recherche canadienne en ce qui a trait à l'utilisation de la technologie éducative. Les données ont été collectées au moyen d'un sondage mené auprès de 557 professeurs et analysées en fonction des deux catégories selon lesquelles Rogers (1995) fait, quant à l'adoption des innovations, une distinction entre les «adeptes précoces» et le courant majoritaire des professeurs. L'article énumère quatre facteurs qui tendraient à créer un «fossé» entre ces deux groupes. Il suggère aussi des moyens permenttant de combler ce fossé et de fournir de l'aide et de l'encouragement à tous les professeurs qui cherchent à intégrer les techonologies éducatives à leur enseignement.

Despite the potential for change and improvement to higher education through the applications of learning technologies (Dolence \& Norris, 1995; Kozma \& Johnston, 1991), adoption and effective use by faculty has been inconsistent and, in many cases, not effective. Although use of technology is increasing (Green, 1997), continued incidents of under-utilized resources and resistance and distrust by both faculty and students indicate that adoption and effective use of learning technologies is problematic at many institutions. Adoption of new technologies is influenced not only by the availability and reliability of useful tools, but also by the cultural and social conditions in which the technology is applied. This paper documents the usage, attitudes and perceptions of barriers to increased use of instructional technologies by the faculty of a large, research university. It further analyses the data by differentiating between those who have been earlier to adopt to the use of technology (Earlier Adopters or EA) and the majority of faculty who have been slower to adopt or have not adopted at all (Mainstream Faculty or MF), focussing on the different demographics, perceptions, and needs of these two groups.

\section{PURPOSE, DEFINITIONS AND RESEARCH QUESTIONS}

The University of Alberta, like most large, research-intensive universities, is struggling to make effective use of new instructional technologies while containing costs and maintaining faculty support and participation. In the fall of 1996, the University developed and administrated a paperbased survey to all full-time faculty members.' The survey had several purposes, including obtaining baseline data on the use of instructional 
technologies, measuring attitudes on a wide variety of technology related issues, and determining perceptions of significant impediments and support relating to adoption of these technologies. The information was used for planning purposes and serves as a means to measure changes over time. A final purpose was to collect information that could be used to help develop the University's Technology Integration Plan. ${ }^{2}$

Instructional technology is variously defined as extending to every teaching aide and system imaginable - from chalkboards to multimedia, sometimes including even processes and practices such as instructional systems design. For the purposes of this study we use the term instructional technology in the more common use of the word as the tools. media and methods developed to facilitate the teaching or learning processes.

This more common definition is used as opposed to ones currently favored by professionals in the field such as the Association for Educational Communications and Technology (AECT) definition. "Instructional Technology is the theory and practice of design, development, utilization, management and evaluation of processes and resources for learning" (Seels \& Richey, 1994, p. 1). As the target audience for the research was faculty who are generally not familiar with the instructional technology literature, we feel comfortable in using the more common definition. However, we acknowledge that instructional technology application has as much to do with design, planning and process as it does with machines.

Some of the specific questions asked in this exploratory investigation include: What is the current usage by academics of instructional technologies, in comparison to the use of information technologies for research and service functions? What are the barriers to increased adoption and are these barriers perceived differently by users and non-users of educational technologies? What type of support and incentives are valued and used by faculty?

\section{REVIEW OF THE LITERATURE}

The introduction of learning technologies, in an environment characterized by a long tradition of unmediated, classroom instruction can be viewed at as a classic case of innovation diffusion. Innovation diffusion research, dominated by the work of Everett Rogers, who has investigated innovation adoption in many fields and professions (e.g., Rogers 1992a, 
1992b, 1993 1995). Rogers theorizes that adoption of innovation occurs inevitably but that there are differences in the rate of that adoption between individuals. He further argues that individual innovation adoption rates are normally distributed and that adopters can be divided into five groups: Innovators, Early Adopters, Early Majority, Late Majority, and Laggards. Moore (1991) argues that a "chasm" exists between the first two categories (Innovators and Early Adopters) and the remaining groups (Early and Late Majorities and Laggards) - at least in regards to marketing strategies. This chasm is illustrated in Figure 1. Geoghegan (1994) applies this "chasm" concept to the adoption of instructional technology in higher education and writes that the chasm "is so significant that it has so far stymied almost all efforts to bridge it. It has left us in a situation in which the early market seems to have approached saturation in its use of instructional technology; but in which mainstream adoptions are relatively few and far between" (p. 8).

Geoghegan notes that most professional development and support efforts, related to instructional technologies, have been orientated toward early technology adopters and have often ignored the "mainstream" instructional faculty. This type of early adopter support is manifest in the proliferation of various "new media centers"3 offering tools, support and expertise to faculty innovators and early adopters. Early adopters are often attracted to the use of learning technology by an interest in the technology itself. MF concerns lie more with the teaching, research, and administrative tasks associated with job requirements and much less with the technologies that, at best, may assist them.

The chasm concept implies that different approaches are needed to cause larger scale increases in the use of instructional technology by MF. Without knowledge of the differences between these two faculty groups, strategies for increasing the use of instructional technology may be relevant and appropriate for only a small portion of faculty.

Geoghegan identifies four factors that exasperate the effort to traverse the chasm between Early Adopters and the majority.

1. Ignorance of the gap. Studies such as this investigation quantify differences between, and develop profiles indicating significant differences between, EAs and MF in regard to demographics, use and attitude towards learning technologies. It is hoped that knowledge of this gap will lead to strategies that help reduce its negative impact on innovation adoption rates. 
Figure 1

\section{Adoption of Innovation}

(Adopted from Geoghegan, Moore \& Rogers)

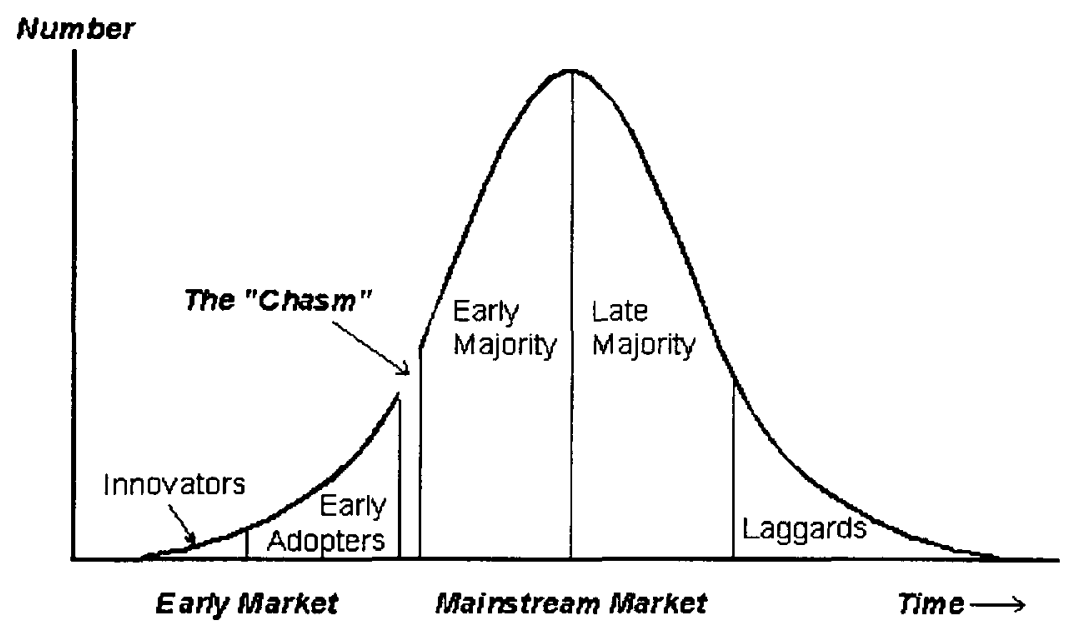

2. The "Technologists' Alliance." Geoghegan notes the problem created by self-serving alliances between groups with special interest in instructional computing. He notes three groups that have created such an alliance: faculty innovators and early adopters, campus instructional technology support staff, and instructional technology vendors. These groups share a common interest in technology that nourishes an exclusive bond that may serve to exclude potential new user groups. This alliance represents a relatively small group of faculty, and may act to exclude a large number of faculty from involvement. Kiesler and Sproull (1987) refer to these alliances as "competence multipliers" which act to push early adopters to ever new skills and experiences, often at the expense of MF. Geoghegan notes "the problem is that only a very small proportion of faculty are actively developing or using such applications, and that once developed, they rarely find their way beyond the 
individuals or teams whose innovative efforts brought them into existence in the first place" (p. 2).

3. Alienation of the Mainstream. Geoghegan points to the alienation of many faculty from the culture of technology, and resentment of the priority and publicity given "high tech projects" which, in a "zero sum" financial system, often decrease funding available for competing academic projects. In addition, the perceived complexity of existing projects create a view among the uninitiated that too much time and expertise is required to create or use these projects. The qualitative questions reported in this study provide powerful illustration of the magnitude of this alienation.

4. Lack of a Compelling Reason to Adopt. Finally, Geoghegan notes that applications are seldom implemented in a way that shows their value in pragmatic, mainstream terms or that clearly demonstrate that the financial benefits clearly exceed the cost of adoption.

This study used quantitative and qualitative data from the campus wide survey to lend empirical support for each Geoghegan's four reasons for the chasm. This paper uses the above framework to help explore ways that instructional technology usage might be stimulated amongst a considerably broader base of university faculty.

\section{SAMPLE}

The survey was mailed to all full time faculty members $(1,487)$ at the University of Alberta in August 1996. No follow-up letter was mailed to faculty. Approximately $37 \%$ (557) of the faculty responded. The survey was sent at a very busy time in the academic schedule, which may account for some non-returns. The survey included six sections and was nineteen pages in length. At the end of the survey, faculty were invited to comment in their own words about any aspect of learning technologies or teaching innovation. Thirty-four percent of respondents (201), took advantage of this opportunity and provided a wealth of qualitative data.

While it is difficult to speculate on the nature of the sample as compared to the population of full time academics, the distribution by academic rank is close to that of the campus population. Further analysis of the data showed that the respondents' distribution by Faculty and age 
was similar to that of the whole population. One could speculate that those most inclined towards use of instructional technology would be more likely to complete the survey. Conversely, there is also the possibility that those most opposed to technological use would also be inclined to complete the survey to make certain that their views are represented. Therefore, it is likely that at least elements of both groups are represented in the sample.

\section{FINDINGS}

The findings will be reported in the six sections: the differences in self-assessed competencies, profiles of the Earlier Adopters, and sections relating to the four factors that contribute to the alleged chasm between EAs and MF.

\section{Instructional Technology Use}

The first task of this investigation was to quantify the use and competencies of faculty relating to use of information technologies. Faculty were asked to self-assess their skills on a number of information technologies (see Figure 2).

Over $90 \%$ of faculty rated their skills at novice or higher at word processing, electronic mail and library database searching. Internet skills (browsing, email list, or newsgroup use) also had over $90 \%$ reporting some use, but the number of users reporting excellent or good level dropped below $50 \%$. The three categories related to production of learning materials (presentation software, WWW page creation and courseware authoring) had much lower rates of self assessed competence. Most faculty report no experience with these instructional tools, with the exception of presentation software such as PowerPoint or Persuasion (with $60 \%$ reporting at least novice skill levels).

We can conclude that faculty are using information tools. Those associated with research (library access, internet and newsgroup browsing) and those primarily associated with professional communication (email, word processing and email lists) report much higher use than those associated primarily with teaching. This finding was further supported by a battery of survey questions designed to determine which areas of scholarly life had most benefited from the use of information technologies. Figure 3 illustrates that the technologies are perceived as having been valuable for those functions directly related to research and 
Figure 2

Self-Assessed Level of Competence with Information Technologies

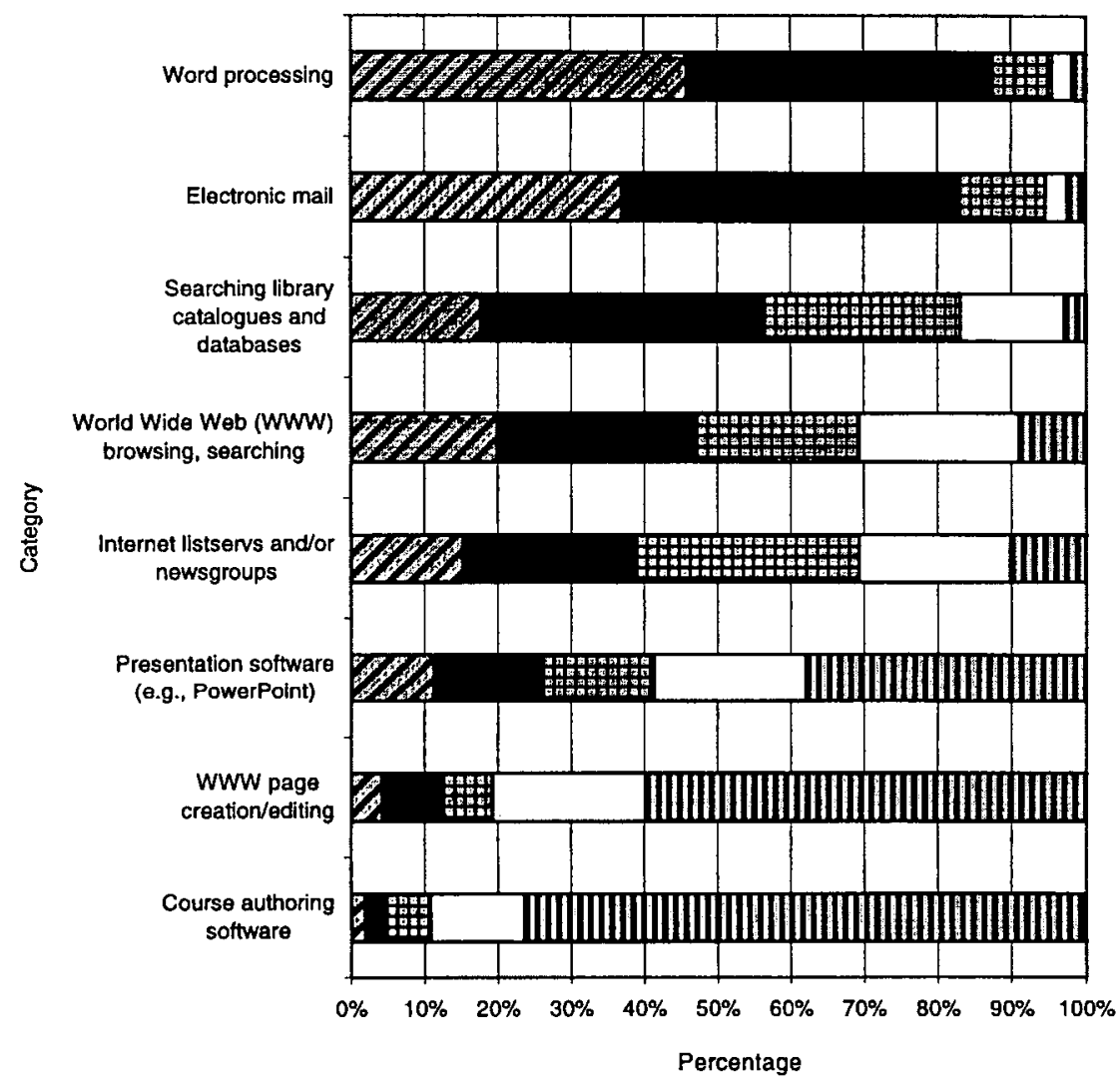

DExcellent agood BFair DNovice BNone


scholarly production of knowledge, including access to library and remote information sources.

Information technologies are perceived as useful in enhancing communications and collaboration between academics. However, less then $43 \%$ of faculty believe that instructional technologies have improved contacts with students, the quality of teaching, or their productivity as teachers.

\section{Defining the Earlier Adopters}

In order to differentiate between earlier adopters of instructional technologies and majority faculty, the self-assessment of technological skill was used to develop a scale. We assume that EAs have come to use these technologies earlier and thus have gained more skill and experience relative to majority faculty. The scale was created by summing scores on each of the eight technologies, where a self-assessment of excellent scored 1, and of none scored 5. As is illustrated in Figure 4, the scores on this technology skill scale approached normality. This is consistent with Rogers' assertion that the rate of adoption of innovation will be normally distributed. Further, Rogers claims that the Innovators and the EAs combined will be about one standard deviation from the mean, or approximately sixteen percent. For the purposes of this study we selected those scoring approximately one standard deviation or lower on the summed scale (approximately 16\%) and assigned them to the EAs. On our scale, the EAs would be those whose self-assessment of competency and use of information technologies was at a higher level than MF.

\section{Earlier Adapter Characteristics}

The EAs group was statistically $(\underline{F}(514,1),=17.3, \underline{p}<.001)$ younger than the MF. EAs were more likely to be members of Science and Engineering and less likely to be members of the Faculty of Arts. Finally, consistent with the age difference, EAs were more likely $(\underline{\mathrm{F}}(1,518)=5.21, \underline{\mathrm{p}}<.05)$ to be at the lower Assistant Professor rank and less likely to be Full Professors.

Faculty were asked to indicate how much time they currently used computer technology. Table 1 illustrates that faculty are generally quite heavy computer users (mode: 3-5 hours/day). As expected, EAs use computers significantly more often $(\underline{F}(1,522)=43.54, \underline{p}<.001)$ than $M F$. 
Figure 3

\section{Faculty Perception of Relative Advantage}

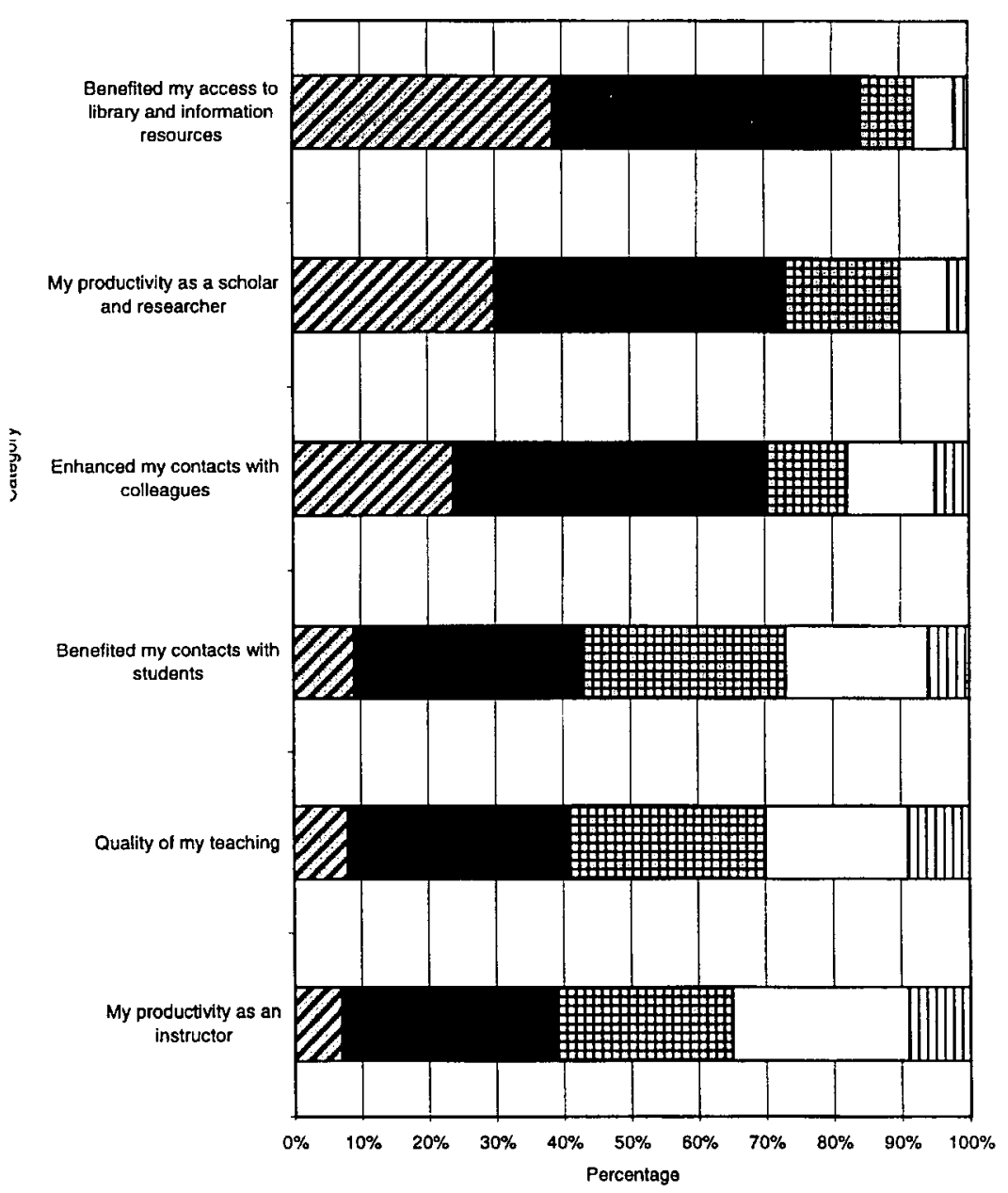

DStrongly Agree Dagree ENeutral DDisagree DStrongly Disagree 
Figure 4

Scale of Technology Self-Assessment

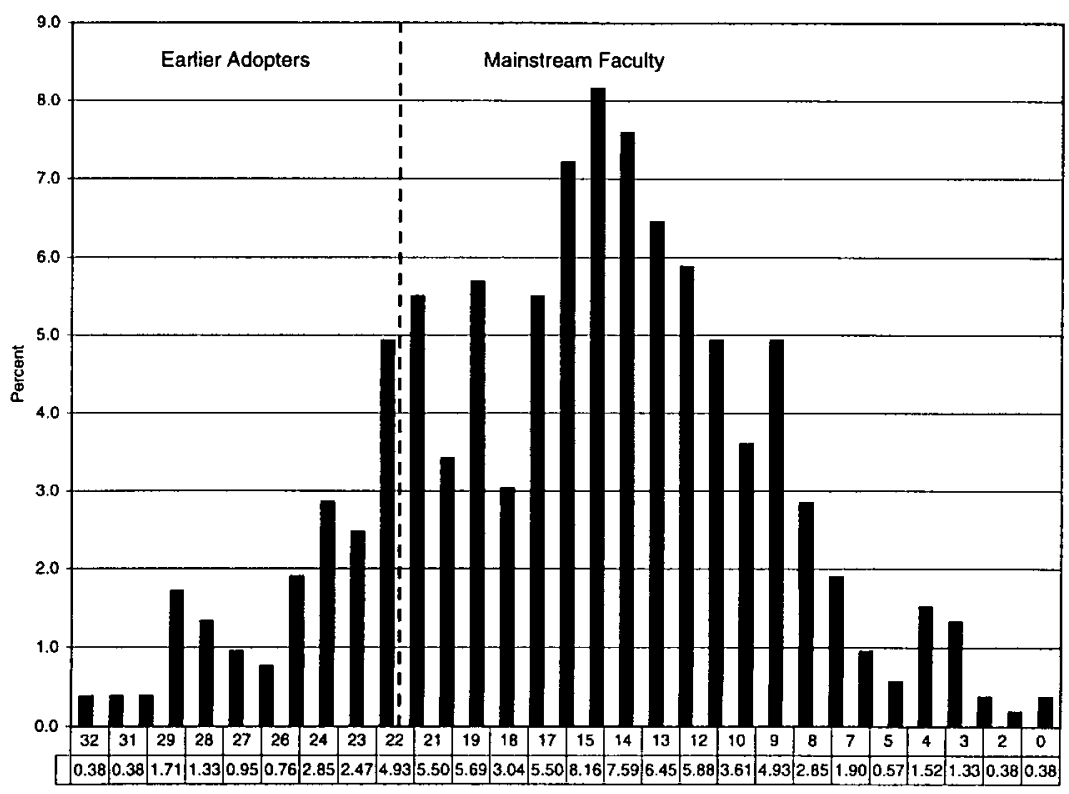

Score on Combined Measures of Technology Self-Assessment

\section{Ignorance of the Gap}

The following findings reveal differences between the EAs and the MF groups. Documenting these differences is important in demonstrating the existence of the gap between EAs and MF faculty.

EAs report higher perceptions of efficacy in the use of information technologies. EAs agreed significantly more $(\underline{F}(1,495)=12.53$, $\mathrm{p}<.001)$ than $\mathrm{MF}$ that technologies had improved the quality of their teaching, benefited their contacts with students $(\underline{F}(1,502)=24.19$, $\mathrm{p}<.001)$, and enhanced contacts with colleagues $(\underline{\mathrm{F}}(1,517)=5.96$, $\mathrm{p}<.05$.). EAs, who are more likely to have used instructional technologies, have noted improved quality of their teaching and have perceived benefit in their communications with students, providing some incentive 
Table 1

\section{Amount of Daily Computer Use}

Category

Less than $1 \mathrm{hr}$.

$1-3$ hrs.

$3-5$ hrs.

More than 5 hrs.
Mainstream Faculty

$12 \%$

$44 \%$

$29 \%$

$13 \%$
Earlier Adopters

$11 \%$

$24 \%$

$39 \%$

to continue using these technologies. These perceptions of efficacy, coupled with demographic differences reported above, indicate that there is a difference between the profiles and attitudes of the two groups.

\section{The "Technologists' Alliances"}

Geoghegan's second reason for the "Chasm" is that technology adoption is supported by an alliance between the EA, the academic technology support units, and software and hardware manufacturers and retailers. He hypothesizes that these groups share an esoteric culture and community that often excludes MF. He argues that a common interest in technology itself rather than its educational application is the critical component of membership in this alliance. Membership provides access to needed support and newly developed software and tools to this select group.

The survey reveals that EAs are not spread evenly amongst faculties and the technologist alliance is also probably not evenly distributed. Table 2 shows the percentage breakdown of EAs and MF of the five largest faculties on campus.

Interestingly, the defining component of the "Alliance" is not whether they belong to the Earlier Adopter group, but whether they are technologically oriented. Those who are familiar with technology for whatever reason, perhaps because of their discipline requirements (e.g., the need to be knowledgeable of technology in the field of engineering), could also become members of this alliance due to this 
Table 2

Five Largest Faculties Proportion of Earlier Adopters and Mainstream Faculty

\begin{tabular}{lcc} 
Faculty & Earlier Adopters & \\
\cline { 2 - 3 } Arts & $9.6 \%$ & Mainstream Faculty \\
Education & $16.7 \%$ & $90.4 \%$ \\
Engineering & $35.0 \%$ & $83.3 \%$ \\
Medicine \& Dentistry & $11.6 \%$ & $65.0 \%$ \\
Sciences & $30.5 \%$ & $88.4 \%$ \\
Campus Total & $18.0 \%$ & $69.5 \%$ \\
\hline
\end{tabular}

shared orientation. While EAs become technology proficient because they develop skills in using technology, the Alliance would likely be made up of more faculty than just the EAs.

Our data indicating the different rates of membership in the Earlier Adopter group by Faculty suggests that membership in Geogehan's Alliance may be better explained by exposure to the technology than through attitudes associated with early adoption and innovations with educational technologies. In less technologically oriented areas, like the Faculty of Arts, the members of this alliance will be those who have had to learn about the technology due to personal interest in technology based instruction, as is the case with the true EAs of instructional technology. In more technologically oriented areas, like the Faculty of Science or Engineering, the Alliance is probably available to a larger group of faculty. However, we are often surprised by the antagonism towards instructional technologies exhibited by some faculty in highly technological fields such as computer science and engineering as revealed in the survey comments.

\section{Alienation of the Mainstream}

The comments from the survey support the notion that alienation exists between MF and the cultural and social underpinnings of technological enhancement to teaching and learning. Overall, the tone of the 
responses was strong, underlining the sense that the adoption, implementation, and support of teaching and learning technologies is not a neutral issue on campus. It is likely that those holding the most passionate views and extreme positions in regard to technology volunteered the most comments. The major themes, which are very much inter-related, are identified below, and illustrated with excerpts from the source data. They are presented in a descriptive manner to allow the "faculty voice" to emerge.

Theme 1 - Faculty feel excluded from the dialogue about technology issues such as investment in technology-based models of teaching and learning, classroom upgrading, and development of distance education initiatives.

There is a sense among many faculty that decisions related to teaching and learning technologies have already been made with no real attempt to involve faculty in the process. The collegial governance of the University community demands that the community of scholars make the important decisions. Given the different experiences, attitudes and skill levels of faculty in regard to instructional technology, it is not surprising to find that many faculty feel excluded from the decision-making process. Some faculty wondered why the University has embarked in this direction in the absence of any 'solid' research on the effectiveness of educational technologies and without a clear mandate from faculty. ${ }^{4}$ There also appears to be confusion about the key motivation for using educational technology. Is it primarily designed to be cost savings through elimination of faculty jobs? Increase learning effectiveness? Improve retention? Change the way teaching is conducted? Improve access? This confusion is illustrated by a professor who writes:

I have yet to see any sound data that shows that new instructional technology is cost effective. The data that I have seen suggest that new technology can be much more expensive than conventional technology and far less effective for educating students. I believe that irresponsible expenditures on new technology and innovation consume valuable resources (dollars, staff and faculty time). I believe that all new initiatives should be monitored and evaluated from a cost benefit point of view.

A number of comments illustrate the differentiation of use of technology between the communication, the research and the teaching applications of the technology. There seems to be much less appreciation or 
experience of benefits to teaching/learning applications as compared to the communication and research benefits:

While I use all the latest computer technology for my research work, I would only foresee using it in a support role in my classroom teaching which will still be based on chalk and blackboard in the near future. I think students can easily be subjected to information overload and the actual learning decreases!

Some faculty members felt under-valued by the institution, and in fact valued less than the potential contributions made by instructional technologies.

Given what is expected of my colleagues, and myself I find the expense and demands of the new technology frustrating and upsetting. I guess in summary, I am overwhelmed by the technology available and particularly how much effort is required to cope with it. And I am totally dismayed by the indifference of the Institution to Faculty and its priority to technology.

In addition, some faculty are actively hostile towards technology, which they seem neither to understand nor appreciate, and certainly are not aware of any potential relative advantage that the technologies may provide.

... the basic assumption behind these questions is false that NEW electronic gadgets will NECESSARILY improve the QUALITY of University teaching. We do not simply deliver information; we help students understand and assess difficult, complex, and challenging ideas; we train sensibilities and intelligence. What a teacher MOST needs is a thorough grasp of his or her discipline, full knowledge of the subject, and the ability to communicate to students (precisely and constructively). A good mind and a trained voice are the only ESSENTIAL tools.

I am not altogether sure what new learning technologies really mean; but it reminds me of the story of the emperor's new clothes. Chalk and a blackboard are all that are needed in my discipline; and money squandered on gimmicks ... might better be spent on replacing cancelled library subscriptions. 


\section{Theme 2 - Fear of impact of technology on the human compo- nent of teaching}

Many faculty seem to equate the use of learning technologies with a decrease in interpersonal communications. Given the capacity of the technology to support and increase asynchronous student-student and student-faculty interaction (email, computer conferencing) this perception indicates that many faculty have not benefited from this communicative capacity. It is obvious that the perception of instructional technology use for many faculty is as a poor substitute for human interaction rather than as a communication enabler.

I believe that all quality university education resides in the HUMAN exchange between teacher and learner. A University should be a place of discussion and armchair thinking which in my view is essential to the learning and research process. Technology cannot and will never replace human contact.

\section{Theme 3 - Conflicting demands on faculty time and resources}

The issues of time constraints, conflicting priorities, training and the need for demonstration models are aptly summed by a faculty member who writes:

... instructors need TIME to learn and experiment with new materials and methods. Simply adding new requirements to the existing workload will lead no where: We need time to learn without jeopardising our research activities, commitments to students, and other responsibilities. Second, instructors need guidance on HOW to use new materials and methods effectively. This guidance needs to be based on systematic research, rather than anecdotes and testimonials from true believers, if our learning time is to be used effectively. Third, we need examples that illustrate the range of PRODUCTIVE possibilities for changing instruction.

Many of the responses to the provided evidence that there exists a great deal of alienation by MF towards technologically based innovation in the teaching function. This alienation is exasperated by a sense of exclusion from decision making, fear of the unknown and untested, and lack of a reward structures and incentives to overcome barriers associated with adoption. 


\section{Lack of Compelling Reasons to Adopt Instructional Technologies}

Barriers. Although most faculty believe $(62 \%)$ that learning and communications technologies are essential to improving the quality of higher education, many barriers were identified to realizing that capacity. Nine factors were identified as major or minor barriers by over $50 \%$ of the faculty (see Figure 5). The greatest barrier identified was lack of institutional or departmental funding. The second greatest barrier was lack of time to learn technologies. Interestingly, EAs rated lack of time as significantly less $(\underline{F}(1,510)=27.73, \underline{p}<.001)$ of a barrier than MF despite the fact that EAs used technologies significantly more than Majority Faculty. This could be because EAs, with their high interest in the technology itself, are more likely to find the time needed to learn the technologies out of personal interest.

Classroom infrastructure and adequate hardware were the third and fourth greatest barriers. The knowledge to apply technology to teaching and information about the technology were also rated as barriers by more than half of the faculty. Not surprisingly, EAs rated information $(\underline{F}(1,498)=36.558, \underline{p}<.001)$ and knowledge $(\underline{F}(1,500)=48.92$, $\mathrm{p}<.001$ ) barriers significantly lower than the MF. One would expect that they are an informed and knowledgeable group in regard to learning technologies. In fact, EAs compared to MF, rated most of the barriers lower, explaining the increased use of technology on the part of EAs.

Incentives. Related to barriers are incentives that help faculty overcome barriers. Five items were identified as important incentives by faculty (see Figure 6). The most important incentives relate to commitment of resources for infrastructure, training and support. The issue of scarcity of resources to finance change and innovation that faculty may wish to undertake is a predominant theme from this study and in the literature (Massy \& Zemsky, 1996: Green \& Gilbert, 1996). The next most important issue concerns recognition of innovation in teaching in tenure and promotion evaluations. Research universities have difficulty in assessing and rewarding teaching in general and innovation related to the teaching function in particular. One respondent commented "only an idiot would spend the time required to develop a course that would truly take advantage of a new delivery technology. Their efforts would only ensure that at Faculty Evaluation Committee time they would get penalized by the bean counters." This lack of incentive is especially critical for younger faculty who, ironically, are the most skilled and interested in using the 
Access to software tools for enhancing my teaching with technology

Central or departmental training and support

Information about available technology

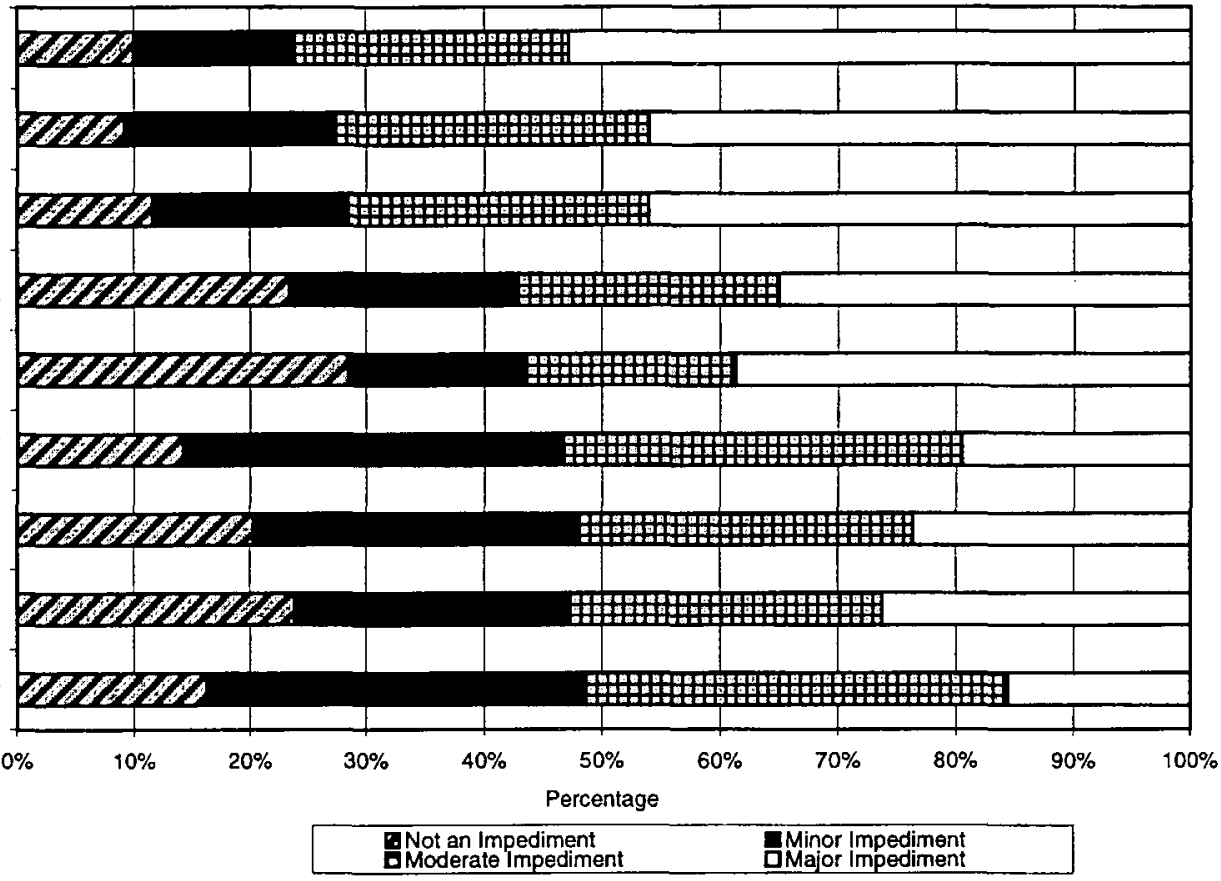




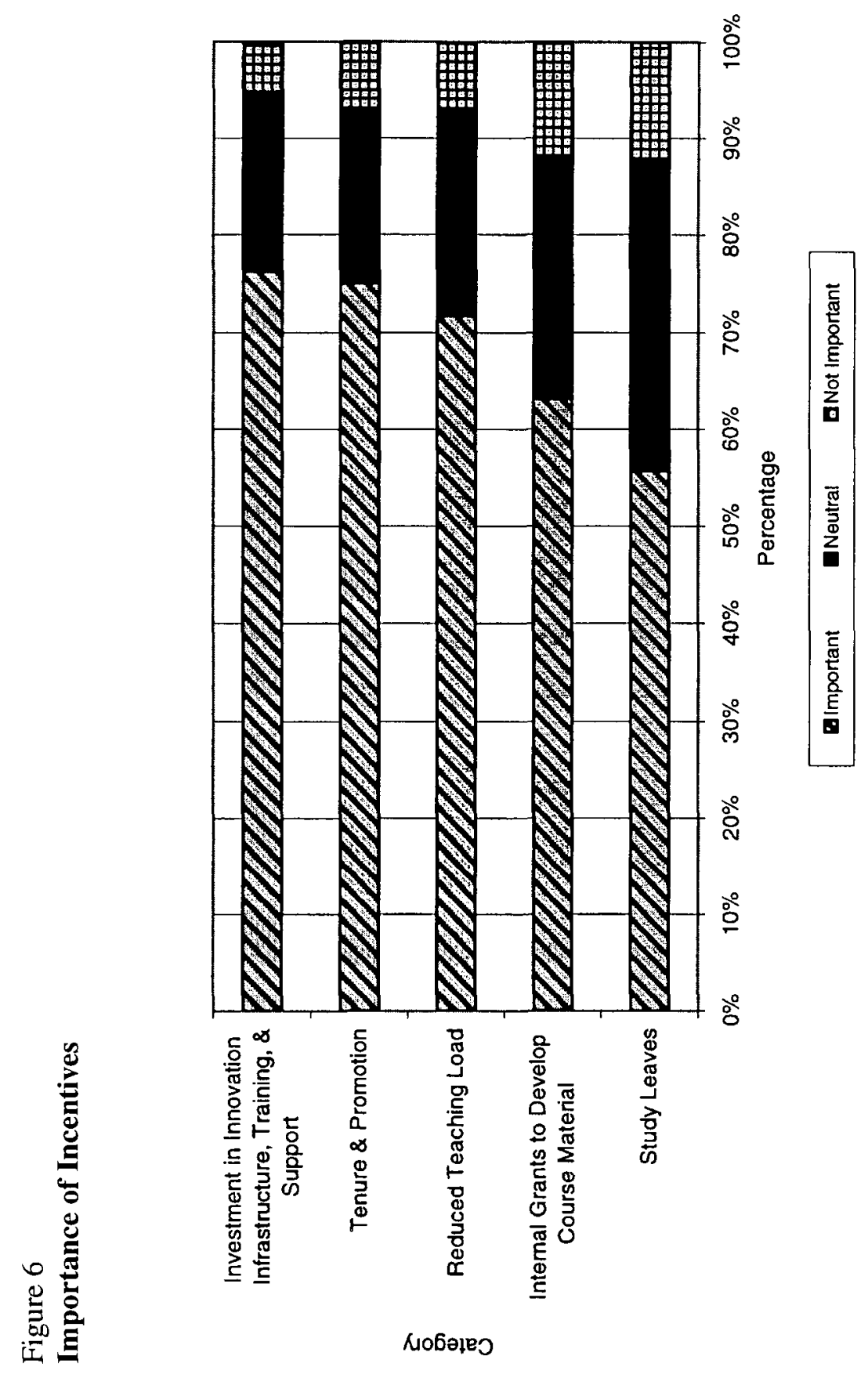

The Canatian Journal of Higher Education Volume XXVII, No. 2, 3, 1998 
technologies and are more highly represented in the EAs group. One young faculty commented:

... as a new faculty member, I have the highest teaching load in the Department, must strive to develop a research program, and am now being solicited to jump on the implementation of technology in teaching bandwagon. In order to survive currently, I must focus on research.

Faculty were asked to rate of a number of incentives as being important, neutral, or not important. The following differences emerged between the EAs and the MF.

Reduced teaching load and study leaves were viewed by most faculty as important incentives. However, EAs rate the reduction of teaching load as significantly more $(\underline{F}(1,514)=5.613, \underline{p}<.05)$ important an incentive than the MF. The value of a reduced teaching load could come from a knowledge of the time commitment required to develop instructional materials or, alternatively, it may indicate a lack of interest and commitment to teaching by EA. If EAs are less committed to the teaching component of academia, this indicates that they may be less capable or interested in serving as role models and champions of the teaching function and advocates of technology used directly and primarily as a teaching tool. EAs were also more likely to view internal grant programs as important.

For all faculty, resources for training and support were identified as the greatest incentive. These resources can be delivered in many ways. Faculty were asked to indicate the format for training and support that was most preferred. The three most popular formats were short blocks of time to learn and practice skills (workshops), working with a mentor, and release time for independent study. It is unlikely that a common format for effective training and support systems can be developed for both EAs and MF. EAs were less interested in scheduled workshops and working with mentors and were significantly more interested in release time for independent study. Having the university require all students to purchase their own computers was identified as an important source of infrastructure and technical support by only $22 \%$ of faculty. EAs rated student ownership of computers as significantly more $(\underline{F}(489,1)=$ $12.08, \mathrm{p}<.001)$ important than Majority Faculty, perhaps because of their interest in the current and potential role of technology, and the perception of the value of increased access through student ownership. 
Innovation requires opinion leaders and change agents to develop and support diffusion networks (Rogers, 1995). Faculty were asked to identify the most important leadership source. Given the supposed collegial nature of University culture, it is not surprising that "colleagues on campus" were the greatest leadership source. Professionals trained in the use of educational technologies were identified as the second most important source, even though there are relatively few such persons employed at the University of Alberta. We found a significant difference $(\underline{F}(506,1)=8.44, \underline{p}<.01)$ between EAs and MF on items related to value of education technology professionals. EAs did not identify these professionals as important leadership sources as often as their MF colleagues. One explanation could be that EAs are self-trained and highly proficient users of technology.

In summary, there exist many barriers and incentives to adoption of instructional technologies. At the University of Alberta, current instructional technology support programming seems oriented more towards EAs than the MF. For example, applications for course development grants, release time, and attendance at workshops seem to be dominated by a relatively small group of EA. To support widespread adoption of instructional technology, efforts and programs must be more carefully tailored to overcome the barriers and provide effective incentives to MF.

\section{DISCUSSION}

The results of this study indicate that adoption of teaching and learning technology is a contentious issue at the University of Alberta. From their usage patterns it is clear that faculty believe that new technologies are effective in enhancing their research function and in assisting in their communications and collaboration with colleagues. However, information technologies are being used much less frequently or effectively for applications related to teaching and learning. Generally faculty believe that the technologies have some potential to aid in the teaching/learning process, but many are deeply suspicious of the way in which this change is being implemented and supported. Paradoxically, many faculty see themselves or colleagues as leadership sources and are less trustful of administration and administrative leaders such as chairs, deans and those who have already adopted the technology. Faculty in our study desired proof that educational technologies will improve learning opportunities and result in efficiencies. Many 
faculty will not become involved in teaching technologies until greater supports and incentives are in place, especially in terms of infrastructure, training and support; tenure and promotion; and release time for course development. Provision of these incentives needs the active support and leadership of administration and government.

Based on the definition used in this paper, the EAs of educational technology represent a younger, more self-reliant group of faculty, who believe that the instructional technologies have enhanced contacts with colleagues and students and improved the quality their learning. EAs also have higher interest in collaboration and in increasing access to University programming. This investigation confirms the four factors identified by Geoghegan (1994) that exacerbate the chasm between EAs and MF.

Ignorance of the gap between these groups has marked many of the programs designed to increase technological use. Many Universities, including the University of Alberta, have developed "new media" centers that provide high-end consulting and access to specialized hardware for faculty development use. An assumption is made that these centers will be used by all members of the faculty. However, these facilities will inherently be more attractive and used by EAs then by MF. To meet the needs of MF, programming associated with these centers must be heterogeneous enough to support new users, the "technology terrified," and those who are not at all interested in "new hobbies" nor in technology for its own sake. Those facilities must be able to demonstrate when technologies can provide relative advantage to these faculty.

Evidence for the second factor, The Technologists' Alliance, is found in the different rates of EAs that were found across Faculties. In general, those Faculties that were more technologically oriented were more likely to have faculty that were classified in the EAs group. We hypothesize that many of these individuals may be comfortable using technologies for other reasons such as job requirements than for an intrinsic interest in adopting the technology for instruction. This would suggest that gaining familiarity with the technology is an important prerequisite that is more necessary in some parts of the university than others. However, it also suggests that campus instructional technology support needs to be planned so as not to exclude those who have had less exposure to the technologies. 
Evidence for Alienation of the Mainstream is found in many of the qualitative responses from the survey. These results indicate that faculty feel excluded from the dialogue about technology, are concerned about the impact of the technology, and feel that technology causes demands on resources and time. Clearly, these concerns need to be addressed before widespread adoption occurs.

Lack of a compelling reason to adopt, was the final factor that exacerbated the gap between EAs and MF. Some of the obstacles included: institution or departmental funding, time to learn the new technology, and classroom infrastructure. Adoption presumes the motivation and resources to overcome the many real and perceived barriers. Some of these barriers can carry considerable risk (e.g., academic promotion). Many of these barriers will need to be removed before widespread adoption takes place.

Compelling reasons that attract MF must be based on pedagogical effectiveness and not reduction in labor or individualized learning alternatives that potentially decrease student-faculty interactions. For example, demonstration or manipulation of content related variables during a computer-based simulation can often teach difficult concepts more effectively than either a lecture or a textbook (Grégoire, Bracewell \& Laferrière, 1996). In this type of application, technologies are tools that can be used to enhance learning - a goal of all instructional staff.

The type of faculty support that will be most effective is different for EAs and MF groups. EAs are capable and interested in teaching themselves how to use the technologies and often only need time to do the work, funding to purchase the equipment and software, and, sometimes some instructional design assistance. Besides these, MF need exposure to new tools, opportunities to take scheduled courses, the assistance of mentors, and opportunities to meet with faculty and department level educational technology specialists.

Many "new media centers" operate with an implicit assumption that the EAs who use the centers will return to their faculties and act as role models, informal consultants and troubleshooters for their colleagues. The psychological, motivational and even age gap between these two groups makes it seem unlikely that EAs will be ideal role models for other faculty. Rogers (1995) notes that it is important to provide incentives for EAs, however once "critical mass" of adoption is approached, it may be more appropriate to focus on rewarding and promoting MF 
adopters, who by definition are more socially integrated and similar to Roger's (1995) "early and late majority" and "laggard" populations.

Many of the qualitative responses to the survey illustrate a deep alienation by some faculty members from the culture of technology and especially the application of technology to the teaching/learning process. Many faculty equate technological use with dehumanization and decrease of human interaction. It is obvious that effective learning/teaching applications need to be developed, evaluated and the results widely circulated. However, the champions of these new applications should not be EAs motivated by an intrinsic interest in the technologies themselves. Rather role models should be MF who are better integrated into the traditional administrative and social norms of faculty culture.

\section{CONCLUSION}

We think it highly likely that the potential benefits of educational technology to communication, information processing and knowledge construction will positively affect the teaching and learning process. If established institutions do not embrace these technologies, then other institutions will arise that take advantage of the technologies and benefit from their application. Comprehensive adoption strategies cannot be based on support of EA, but must be designed to appeal to the MF and take into account the incentives, training programs and barriers identified by this group. The results of this study indicate that although information technologies have been adopted by MF for research and professional communications applications, the teaching and learning applications lag behind. Teaching and learning applications represent new frontiers with challenges and potential rewards for those institutions who are willing to make the cultural and economic adjustments necessary to support adoption.

\section{RECOMMENDATIONS FOR PRACTICE}

This study pointed out many of the challenges faced by the University of Alberta in adopting educational technologies to enhance the teaching and learning process. The following four recommendations were distilled from the data and are designed to help the University community address faculty concerns. The recommendations were developed 
for a single university, but we feel they are relevant to varying degrees among most research Universities.

\section{Research and Evaluation}

a. Make faculty aware of the established research base in the field of educational technology providing examples and evidence for a "compelling reason" to change.

This could be accomplished through a number of means, including occasional papers or published reports of research both on and off this campus, available through print media and on the WWW; participation in a research network; annual public forums; presentation at departmental and faculty meetings and the establishment of a well-indexed (query-able) database of published research.

b. Provide an active program of, and support and consultation for, research using educational technologies.

The accomplishments of local champions and EAs operating within the social network of the institution must be documented and celebrated. Initially, this program could be developed and implemented by academics trained in educational technology but over time should be become part of the regular research program of the various Faculties. We have found that only through publication in credible, peer reviewed journals can the "scholarship of teaching" (Boyer, 1990) be acknowledged and appropriately rewarded.

\section{Training and professional development}

Provide multiple training opportunities in using technology for teaching, learning, and research. No single model of training will meet the diverse demands from faculty.

a. Develop an active program of training through noon-hour workshops, show and tell exposure sessions, peer demonstrations of ongoing work, intensive multi-day institutes, and extended training sessions.

b. Provide "just-in-time" training to meet personal needs as they emerge. 
Programs of in-service training and workshops are essential for raising awareness and to assist individuals to develop a network. However, developmental change most often occurs at the moment of personal need for an innovation. "Just-in-time" training responds to the need to establish a system of professional development using individualized and asynchronous technologies such as computer-assisted learning, WWW exploration sites and archived computer conference sessions.

c. Support one-on-one training from colleagues and peers and the development of mentoring opportunities.

\section{Strategic Planning}

a. Upgrade teaching spaces (both for on and off-campus delivery) on a strategic basis.

A clear plan must be put in place and communicated to faculty with regard to the upgrading of basic teaching facilities. Access to tools is a "necessary prerequisite," but insufficient in the absence of incentives and training opportunities.

b. Strategic planning, department by department, that ensures that faculty have input into decisions regarding teaching/ learning technologies. Each department must identify real problems and apply technologies that have most promise to address these needs. Technology driven solutions rarely meet real needs or solve real problems.

c. Focus on applications, niche areas and specialties where advantages of accessibility, increased opportunities for learner control and economy of scale will be most cost and learning effective.

\section{Rewards}

Review the reward, tenure and promotion process of each faculty to ensure that skillful innovation and improvement to the teaching/learning process is rewarded on an equivalency basis to the rewards for demonstration of excellence in research. Most, faculty will not devote the necessary effort to achieve competence and apply learning technologies to their teaching if they perceive that such effort will go either un-rewarded (or even penalized) within the tenure and promotion process. 


\section{Notes}

I A copy of the survey is available at:

http://www.library.ualberta.ca/lss/survey.pdf and the detailed results at: http://www.ualberta.ca/REPORTS/FACULTYSURVEY/

2 University's Technology Integration Plan: http://www.ualberta.ca/REPORTS/LearningFirst.html

3 New media centres: http://www.csulb.edu/gc/nmc/

4 Of course, considerable evidence related to effective use of instructional technology does exists but many faculty have never been exposed to this literature.

\section{References}

Boyer, E. (1990). Scholarship reconsidered: Priorities of the professoriate. Princeton, NJ: Carnegie Foundation for the Advancement of Teaching.

Geoghegan, W.H. (1994). Whatever happened to instructional technology? IBM Academic Consulting. Paper presented at the 22nd Annual Conference of the International Business Schools Computing Association. Baltimore, Maryland (July 17-20). [On-line]. Available on line: http://www.hied.ibm.com/news/whitep/whg/wpi.htm

Grégoire, R. Bracewell, R., \& Laferrière, T. (1996). The contribution of new technologies to learning and teaching in elementary and secondary schools (1996, Aug. 2). [On-line]. Available on line:

http://www.fse.ulaval.ca/fac/tact/fr/html/impactnt.html

Green, K. (1997) Campus computing. The eighth national survey of desktop computing and information technology in higher education. Encino, CA: Campus Computing.

Green, K., \& Gilbert, S. (1995). Great expectations: Content communication productivity and the role of information technology in higher education. Change. 27(2), 8-19.

Kiesler, S., \& Sproull, L. (Ed.). (1987). The social process of technological change in organizations. Cambridge: Cambridge University Press, 28-40.

Kozma, R.B., \& Johston J. (1991). The technological revolution comes to the classroom. Change 23(1), 10-23.

Massy, W., \& Zemsky, R. (1996). Information technology and academic productivity. Educom Review, 3l(1), 12-15.

Moore, G.A. (1991). Crossing the chasm: Marketing and selling technology products to mainstream customers. New York, NY: Harper Business.

Rogers, E. (1992a). Prospectus for a cooperative extension system in education. Knowledge: Creation, Diffusion, Utilization. 13(3), 248-255. 
Rogers, E (1992b). On early mass communications study. Journal of Broadcasting \& Electronic Media. 36(4), 467-471.

Rogers, E (1993). In T.E. Backer \& E. M. Rogers (Ed.), Organizational aspects of health communication campaigns: What works? (pp. 139-162). Newbury Park, CA: Sage Publications.

Rogers, E. (1995). Diffusion of innovations (4th ed.). New York, NY: Simon \& Shuster.

Seels, B. \& Richey, R. (Eds.) (1994). Instructional technology: The definition and domains of the field. Washington, DC: AECT. 